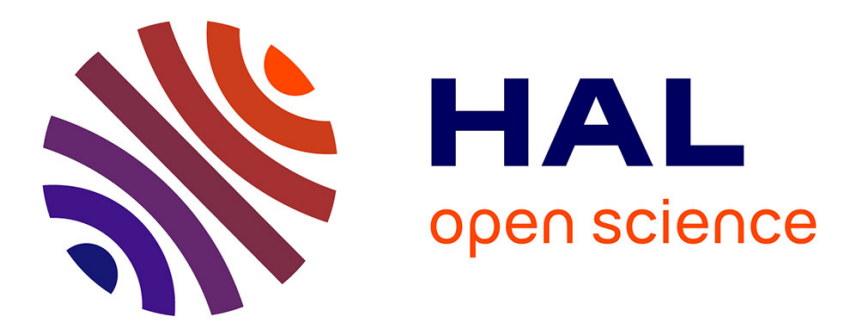

\title{
Identification of metabolomic markers of lavender and lavandin essential oils using mid-infrared spectroscopy
}

Sofia Lafhal, Pierre Vanloot, Isabelle Bombarda, Jacky Kister, Nathalie Dupuy

\section{- To cite this version:}

Sofia Lafhal, Pierre Vanloot, Isabelle Bombarda, Jacky Kister, Nathalie Dupuy. Identification of metabolomic markers of lavender and lavandin essential oils using mid-infrared spectroscopy. Vibrational Spectroscopy, 2016, 85, pp.79-90. 10.1016/j.vibspec.2016.04.004 . hal-01451397

\author{
HAL Id: hal-01451397 \\ https://hal.science/hal-01451397
}

Submitted on 12 Apr 2018

HAL is a multi-disciplinary open access archive for the deposit and dissemination of scientific research documents, whether they are published or not. The documents may come from teaching and research institutions in France or abroad, or from public or private research centers.
L'archive ouverte pluridisciplinaire HAL, est destinée au dépôt et à la diffusion de documents scientifiques de niveau recherche, publiés ou non, émanant des établissements d'enseignement et de recherche français ou étrangers, des laboratoires publics ou privés. 


\title{
Identification of metabolomic markers of lavender and lavandin essential oils using mid-infrared spectroscopy
}

\author{
Sofia Lafhal, Pierre Vanloot, Isabelle Bombarda, Jacky Kister, Nathalie Dupuy* \\ Aix Marseille Université, LISA, EA4672, Equipe METICA, 13397 Marseille cedex 20, France
}

\begin{abstract}
A B S T R A C T
Lavender (Lavandula angustifolia) and lavandin (sterile hybrid of L. angustifolia P. Mill. $\times$ Lavandula latifolia (L.f.) Medikus) are widely cultivated in the Mediterranean area for produce essential oils. In this study, 80 lavandin and 55 lavender essential oil samples from various varieties were analyzed. Firstly, a chemometric treatment of mid-infrared spectra was used to evaluate the capacity of Partial Least Squares Discriminant Analysis (PLS-DA) regression to discriminate French lavandin and lavender essential oil (EO) samples and their varieties (Abrial, Fine, Grosso, Maillette, Matherone, Sumian and Super), and secondly, to quantify the main compounds such as linalyl acetate, linalool, eucalyptol and camphor by PLS regression using reference data from gas chromatography. The examination of PLS and PLS-DA regression coefficients allowed the identification of metabolomic markers. The lavender/lavandin EOs and their varieties were very well classified (100\% for lavender/lavandin EOs and between 98 and 100\% for varieties). The calibration models obtained by PLS regression for the determination of the main compound contents revealed good correlation $(\geq 0.86)$ between the predicted and reference values. This method can be used to control the authenticity and traceability of lavender/lavandin and their varieties. Finally, mid-infrared and Raman spectroscopy results were compared.
\end{abstract}

\section{Introduction}

Thirty nine lavandula species plus a number of hybrids and intraspecific taxa, mostly of Mediterranean origin, compose the lavandula family (Lamiaceae). Among them, Lavandula angustifolia (lavender) and its hybrid (lavandin) differ essentially in their chemical composition. Lavender/lavandin essential oils are obtained from lavender/lavandin by hydro-distillation. The quality of the oil depends on three main factors: the quality of the plant, the time of harvest, and the distillation process.

Lavender essential oils are used in perfumes and aromatheraphy. The essential oil produced from $L$. angustifolia is the most suitable for use in perfumes, due to it high linalool content [1,2]. Lavandin essential oils are used in soap, detergents and cosmetics, because of their high camphor content [2-8].

Lavandin is a hybrid between L. angustifolia P. Mill. and Lavandula latifolia (L.f.) Medikus. Among its varieties (Abrial, Grosso, Sumian and Super), Grosso is the most famous for its essential oil yield. Among the main lavender varieties (Fine, Maillette and Matherone), the Fine lavender is the most famous for

\footnotetext{
* Corresponding author.

E-mail address: nathalie.dupuy@univ-amu.fr (N. Dupuy).
}

the same reason, while the Matherone variety is currently less cultivated.

As has been said, Lavender species differ in their chemical composition, and logically so do their hybrids and the essential oils they produce when distilled. Lavender and lavandin oils contain more than one hundred compounds, including linalyl acetate, linalool, camphor, borneol, eucalyptol and $\beta$-caryophyllene, each contributing to the chemical and sensory properties of the oil. The major distinction between the two essential oils lies in their relative contents of linalyl acetate, linalool, eucalyptol and camphor.

The chemical composition can be determined using gas chromatography and gas chromatography-sniffing $[9,10]$. These methods are usually applied for the purpose of quality control and selection of high-quality plants, but they are very time-consuming, and attempts have been made to find alternative analytical methods.

In this context, vibrational spectroscopy methods (nearinfrared, mid-infrared (MIR) and Raman spectroscopies) combined with chemometric treatments have been successfully introduced for a non-destructive determination of metabolites present in essential oils [11-22]. Momentarily, it is only by applying statistical methods that EOs near-infrared spectra can be interpreted, 
whereas the bands that are characteristic of the individual compounds can easily be seen in the MIR and Raman spectra, therefore making it possible to discriminate between essential oils. MIR spectroscopy is a tool for research and data analysis which is well-known and widely used. During the past ten years, MIR spectroscopy has increasingly been used in the food industry. Vegetable oils including olive oil constitute an important group of food products for which MIR spectroscopy has successfully been applied to characterize French olives, to authenticate vegetable oils and to distinguish the geographic origin of extra virgin olive oils [23-26]. Whatever its acquisition mode, attenuated total reflection (ATR) or transmission cell accessories for Fourier-transform infrared (FT-IR) spectroscopy can be used to quantify, authenticate, identify and classify fats, fatty oils or essential oils.

Currently in various studies, analytical data have been treated using chemometric methods such as Principal Component Analysis (PCA) [27,28], Soft Independent Modelling of Class Analogies (SIMCA) [13] and Partial Least Squares (PLS) Regression [29,30].

The first part of this paper considers the potential of MIR spectroscopy for discriminating between the two EOs and the seven varieties. Then in the second part, the combination of MIR spectroscopy and chemometric methods to quantify terpenoids in EOs is presented, along with the identification of the metabolomic markers of the varieties. In the last part, a comparison with previous results from Raman spectroscopy used to determine the original varieties of lavender and lavandin OEs [31] is given.

\section{Materials and methods}

\subsection{Essential oil samples}

In total, 135 samples were analyzed including 80 lavandin oil samples and 55 lavender oil samples from several varieties. The lavender and lavandin were L. angustifolia Miller and its hybrid, i.e. L. angustifolia Miller $\times$ L. latifolia Linnaeus fils Medikus, French type, which had been harvested in 2012, 2013 and 2014 in various French collection areas (unknown department (00), Alpes-deHaute-Provence (04), Ardèche (07), Drôme (26) and Vaucluse (84)). Samples were divided into varieties: Fine (FI, $n=19)$, Maillette (MA, $n=24)$ and Matherone (MT, $n=12$ ) varieties for lavender samples and Abrial (AB, $n=15$ ), Grosso (GR, $n=30$ ), Sumian (SU, $n=16$ ) and Super (SP, $n=19$ ) varieties for lavandin samples.

\subsection{Pure standard substances}

Pure standard substances - 3-octanone, lavandulyl acetate, linalyl acetate, linalool, borneol, camphor, $\beta$-caryophyllene and eucalyptol - were purchased from Sigma Aldrich (Steinheim, Germany), Adrian (Aix-les-Milles, France), Lavender France (Montguers, France), Fluka (Buchs, Switzerland), Alpha Aesar (Karlsruhe, Germany), Alpha Aesar (Karlsruhe, Germany), TCI Europe (Zwijndrecht, Belgium) and Merck (Schuchardt, Germany) respectively.

\subsection{Gas chromatography (GC)}

\subsubsection{GC-MS analysis}

GC-MS analyses were performed on a 7890A GC system coupled with a 5975C VL mass spectrometer detector (Agilent Technologies) equipped with a HP-5MS capillary column (J\&W Scientific, $30 \mathrm{~m} \times 0.25 \mathrm{~mm}, 0.25 \mu \mathrm{m}$ film thickness). Data acquisition and processing were performed using the MSD Chemstation E.01.01.335 (Agilent) software. $1 \mu \mathrm{L}$ of diluted essential oil ( $80 \mu \mathrm{L}$ in $1.5 \mathrm{~mL}$ of ethanol) was injected. The experimental conditions developed in the laboratory were: solvent delay, $2 \mathrm{~min}$; programmed column temperature: $2 \mathrm{~min}$ at $80^{\circ} \mathrm{C}$, then $80^{\circ} \mathrm{C}$ to $200^{\circ} \mathrm{C}$ $\left(5^{\circ} \mathrm{C} / \mathrm{min}\right)$, then $200^{\circ} \mathrm{C}$ to $260^{\circ} \mathrm{C}\left(20^{\circ} \mathrm{C} / \mathrm{min}\right)$, final temperature held for $5 \mathrm{~min}$; injector (split ratio 60) and detector temperature: $250^{\circ} \mathrm{C}$; carrier gas: helium (flow rate $1.2 \mathrm{~mL} / \mathrm{min}$ ); ionisation voltage $70 \mathrm{eV}$; electron multiplier, $1 \mathrm{kV}$.

\subsubsection{GC-FID analysis}

GC analyses were performed on a 7890A GC (Agilent Technologies) system with a flame ionisation detector (FID) equipped with a HP5 capillary column (J\&W Scientific, $30 \mathrm{~m} \times 0.25$ $\mathrm{mm}, 0.25 \mu \mathrm{m}$ film thickness). Data acquisition and processing were performed using the Chemstation B.04.03-SP1 (87) (Agilent) software. The experimental conditions were the same as given for the GC-MS analyses. Hydrogen was the carrier gas at a flow rate of $1.2 \mathrm{~mL} / \mathrm{min}$. Linear retention indices were calculated with reference to $n$-alkanes (C8-C28).

\subsection{Spectroscopy}

\subsubsection{MIR spectroscopy}

The spectra of each lavender or lavandin oil sample were recorded within the $1800-650 \mathrm{~cm}^{-1}$ spectral range with $4 \mathrm{~cm}^{-1}$ resolution and 64 scans, on a Nicolet Avatar spectrometer equipped with a MCT/A detector, an Ever-Glo source, and a $\mathrm{KBr} /$ germanium beam splitter. The MIR spectrometer was situated in an air-conditioned room $\left(21^{\circ} \mathrm{C}\right)$. Samples were deposited without preparation on an Attenuated Total Reflection (ATR) accessory provided with a diamond crystal. Air was taken as reference for the background spectrum collected before each sample under the same conditions. After each spectrum, the ATR plate was cleaned with ethanol solution, allowing the ATR crystal to dry. Cleanliness was verified by collecting a background spectrum and comparing it with the previous background spectrum.

\subsubsection{Raman spectroscopy}

Spectra were collected with an Almega (Thermo-fisher Scientific Nicolet) Raman spectrometer equipped with a $\mathrm{Nd}$ : $\mathrm{YVO}_{4}$ diode-pumped solid-state (DPSS) laser $(532 \mathrm{~nm})$. The minimum and maximum powers at the output of the laser head were 15 and $150 \mathrm{~mW}$, respectively. All spectra were taken using the $180^{\circ}$ backscattering geometry. The detector was a charge coupled device (CCD). Samples were placed in a quartz cell $(2 \mathrm{~mm})$ and the spectra were recorded with $2 \mathrm{~cm}^{-1}$ resolution and two accumulations of $15 \mathrm{~s}$ each at full laser power in the range $4000-90 \mathrm{~cm}^{-1}$ using the Omnic 7.2 software (Thermo-fisher Scientific Nicolet). The Raman spectrometer was situated in an air-conditioned room $\left(21^{\circ} \mathrm{C}\right)$.

During data preprocessing, the Extended Multiplicative Signal Correction (EMSC) was used to correct unwanted variation effects, such as diffusion effect. In this study samples are not filtered. Some of them contain airborne particles and are very slightly colored. EMSC contributes to making subsequent calibration model simpler and statiscally more robust. The number of factors used for modelling is reduced and RMSEP is slightly improved [32]. All EMSC-pretreated spectra, constitute the matrix used to perform PCA and most PLS regressions.

\subsection{Chemometric analysis}

PCA [33] is an unsupervised modelling method, also known as projection method, and it is often the first step in exploratory data analysis aiming to find patterns in the data. The procedure establishes a linear spectral model which allows original and correlated variables (absorbance) to be converted into uncorrelated variables called principal components or loading. These latent variables contain the main information and are calculated from 
spectral differences and similarities. The procedure also reduces data with no information loss: generally, a small number of principal components is sufficient to summarize the available spectral information. Therefore every EO spectrum can be considered as a sum of principal components weighted by scores. The representation of these components appears as a spectral profile (spectral decomposition model) which is meaningful for a spectroscopy user. PCA is oriented towards modelling the variance/ covariance structure of the data matrix into a model, which is based on the significant spectral differences (significant scores) [34] and considers noise as an error. The number of principal components depends on the model complexity. Generally, the first component extracts the largest source of variance and the last one only extracts noise.

PLS regression [35,36] is a powerful multicomponent analysis that overcomes the interferences and information overlaps inherent to any supervised analysis of the relation between signal intensity and the Y variable. PLS allows a sophisticated statistical approach using a spectral region rather than unique and isolated analytical bands [37,38]. The algorithm is based on the ability to mathematically correlate spectral data to a property matrix of interest, while simultaneously taking into account all other significant spectral factors that perturb the spectrum. It is thus a multivariate regression method that uses a selected spectral region and is based on the use of latent variables. To construct a model, the first step is to perform a calibration. This involves collecting a calibration set of reference samples, which should contain all chemical and physical variations that are expected to occur in the unknown samples and that will be used in the prediction set. The purpose of this calibration is to establish a multiple linear regression between the MIR spectra and the various parameters of the sample set. The second step consists in a model validation using a prediction set (different from the calibration set), i.e., the values obtained from the model are compared with the values obtained with the reference method.
As is known, the first PLS loading vector estimates the covariance vector between the measured spectrum and the component concentration, as detailed in the past by several studies $[39,40]$. The evaluation of errors in calibration and prediction was carried out by computing the standard error of calibration (SEC) and the standard error of prediction (SEP).

Another useful parameter is the relative error of prediction $(R E P)$, which shows the predictive ability of the model, calculated from the equation:

$R E P=\frac{S E P}{\bar{y}} \times 100$

where $\bar{y}$ is mean values of components. SEC,SEP and REP should be as small as possible.

Partial Least Squares Regression has not previously been employed in pattern recognition problems such as classification for this specific application to lavender/lavandin EOs. However, this technique can be adapted for classification, giving rise to the Partial Least Squares-Discriminant Analysis (PLS-DA) regression method [41]. PLS-DA is carried out using an exclusive binary coding scheme with one bit per class. For the codification of samples, the two EOs corresponding to lavender and lavandin were arbitrarily classified in that order. For instance, a lavender sample was codified by the vector $\{1 ; 0\}$. The sample was then assigned to the class having the highest membership value. As it is difficult to calibrate and predict samples with binary variables, it was necessary to grade the results between the values 0 or 1 . Samples with values lower than 0.5 and higher than 1.5 were identified. as outside the defined origin and samples with values between 0.5 and 1.5 were identified as belonging to the defined origin. The same protocol was used to predict varieties. For the codification of samples, the seven varieties corresponding to AB, GR, SU, SP, FI, MA and MT were arbitrarily classified in that order. For instance, an $A B$ sample was codified by the vector $\{1 ; 0 ; 0 ; 0 ; 0 ; 0 ; 0\}$.

Table 1

Chemical composition of lavender EO varieties (mass fraction in\% as obtained by GC).

\begin{tabular}{|c|c|c|c|c|c|c|c|c|c|c|c|c|c|}
\hline \multirow[t]{2}{*}{$R I^{\mathrm{a}}$} & \multirow[t]{2}{*}{ Compounds } & \multicolumn{3}{|c|}{ FI $(n=19)$} & \multicolumn{3}{|c|}{ MA $(n=24)$} & \multicolumn{3}{|c|}{$\operatorname{MT}(n=12)$} & \multicolumn{3}{|c|}{ lavender $(n=55)$} \\
\hline & & $\min$ & $\max$ & mean & $\min$ & $\max$ & mean & $\min$ & $\max$ & mean & $\min$ & $\max$ & mean \\
\hline 923 & $\alpha$-Pinene & 0.00 & 0.33 & 0.16 & 0.00 & 0.17 & 0.07 & 0.00 & 0.16 & 0.07 & 0.00 & 0.33 & 0.10 \\
\hline 944 & Camphene & 0.00 & 0.20 & 0.10 & 0.11 & 0.34 & 0.20 & 0.00 & 0.11 & 0.08 & 0.00 & 0.34 & 0.13 \\
\hline 973 & Sabinene & 0.12 & 0.66 & 0.33 & 0.21 & 0.62 & 0.39 & 0.15 & 0.61 & 0.31 & 0.12 & 0.66 & 0.34 \\
\hline 980 & $\beta$-Pinene & 0.00 & 0.31 & 0.07 & 0.00 & 0.14 & 0.03 & 0.00 & 0.08 & 0.02 & 0.00 & 0.31 & 0.04 \\
\hline 985 & 3-Octanone & 0.30 & 1.60 & 0.79 & 0.75 & 1.98 & 1.31 & 0.13 & 0.74 & 0.35 & 0.13 & 1.98 & 0.82 \\
\hline 989 & $\beta$-Myrcene & 0.17 & 0.85 & 0.39 & 0.15 & 0.64 & 0.33 & 0.25 & 0.57 & 0.42 & 0.15 & 0.85 & 0.38 \\
\hline 1012 & Hexyl acetate & 0.11 & 0.41 & 0.25 & 0.18 & 0.60 & 0.35 & 0.00 & 0.28 & 0.09 & 0.00 & 0.60 & 0.23 \\
\hline 1030 & Limonene & 0.16 & 0.66 & 0.31 & 0.06 & 0.33 & 0.14 & 0.00 & 0.23 & 0.10 & 0.00 & 0.66 & 0.18 \\
\hline 1034 & Eucalyptol $^{\mathrm{b}}$ & 2.69 & 5.88 & 4.05 & 0.80 & 2.92 & 1.44 & 3.89 & 8.43 & 5.94 & 0.80 & 8.43 & 3.81 \\
\hline 1044 & trans- $\beta$-Ocimene & 2.18 & 4.69 & 2.95 & 0.38 & 2.86 & 1.00 & 5.09 & 10.71 & 7.32 & 0.38 & 10.71 & 3.76 \\
\hline 1073 & Linalool oxide & 0.10 & 0.24 & 0.17 & 0.24 & 0.54 & 0.40 & 0.07 & 0.20 & 0.12 & 0.07 & 0.54 & 0.23 \\
\hline 1087 & $\alpha$-Terpinolene & 0.00 & 0.23 & 0.11 & 0.00 & 0.50 & 0.20 & 0.00 & 0.20 & 0.08 & 0.00 & 0.50 & 0.13 \\
\hline 1098 & Linalool & 17.94 & 31.82 & 27.07 & 23.82 & 50.20 & 39.56 & 14.28 & 25.40 & 20.38 & 14.28 & 50.20 & 29.00 \\
\hline 1106 & Octen-1-ol acetate & 0.46 & 1.29 & 0.92 & 0.39 & 1.61 & 0.66 & 0.71 & 1.35 & 0.91 & 0.39 & 1.61 & 0.83 \\
\hline 1145 & Hexyl isobutyrate & 0.00 & 0.17 & 0.08 & 0.00 & 0.10 & 0.06 & 0.00 & 0.10 & 0.03 & 0.00 & 0.17 & 0.06 \\
\hline 1150 & Camphor & 0.19 & 1.04 & 0.34 & 0.26 & 0.91 & 0.55 & 0.19 & 0.43 & 0.29 & 0.19 & 1.04 & 0.39 \\
\hline 1168 & Lavandulol & 0.48 & 2.13 & 0.99 & 0.00 & 1.32 & 0.16 & 0.48 & 4.28 & 1.62 & 0.00 & 4.28 & 0.92 \\
\hline 1171 & Borneol & 0.75 & 1.50 & 1.12 & 1.01 & 2.39 & 1.72 & 0.58 & 1.32 & 0.89 & 0.58 & 2.39 & 1.24 \\
\hline 1183 & Terpinen-4-ol & 2.10 & 8.11 & 4.18 & 0.07 & 1.07 & 0.35 & 1.15 & 2.54 & 1.77 & 0.07 & 8.11 & 2.10 \\
\hline 1193 & Hexyl butyrate & 0.23 & 0.47 & 0.35 & 0.24 & 0.73 & 0.53 & 0.00 & 0.40 & 0.13 & 0.00 & 0.73 & 0.34 \\
\hline 1197 & $\alpha$-Terpineol & 0.17 & 1.47 & 0.71 & 0.09 & 1.10 & 0.70 & 0.18 & 1.37 & 0.82 & 0.09 & 1.47 & 0.74 \\
\hline 1260 & Linalyl acetate & 34.66 & 43.18 & 38.28 & 31.63 & 51.69 & 39.79 & 36.29 & 45.79 & 39.87 & 31.63 & 51.69 & 39.31 \\
\hline 1293 & Lavandulyl acetate & 2.58 & 10.43 & 4.61 & 0.24 & 2.05 & 0.71 & 2.77 & 7.06 & 5.14 & 0.24 & 10.43 & 3.49 \\
\hline 1386 & Geranyl acetate & 0.20 & 0.86 & 0.53 & 0.08 & 0.79 & 0.52 & 0.13 & 0.87 & 0.48 & 0.08 & 0.87 & 0.51 \\
\hline 1429 & $\beta$-Caryophyllene & 3.63 & 6.11 & 5.02 & 2.65 & 6.54 & 3.70 & 4.92 & 7.07 & 6.06 & 2.65 & 7.07 & 4.93 \\
\hline 1460 & $\beta$-Farnesene & 0.49 & 2.50 & 1.73 & 1.38 & 2.35 & 1.84 & 2.06 & 3.56 & 2.94 & 0.49 & 3.56 & 2.17 \\
\hline 1492 & Germacren D & 0.44 & 1.55 & 0.82 & 0.14 & 0.55 & 0.27 & 0.47 & 0.89 & 0.67 & 0.14 & 1.55 & 0.59 \\
\hline 1594 & Caryophyllene oxide & 0.29 & 0.79 & 0.52 & 0.29 & 0.94 & 0.48 & 0.25 & 0.82 & 0.46 & 0.25 & 0.94 & 0.49 \\
\hline
\end{tabular}

a $R$ : Retention indices on HP-5 capillary column.

b cis- $\beta$-ocimene. 
Table 2

Chemical composition of lavandin EO varieties (mass fraction in\% as obtained by GC).

\begin{tabular}{|c|c|c|c|c|c|c|c|c|c|c|c|c|c|c|c|c|}
\hline \multirow[t]{2}{*}{$R I^{\mathrm{a}}$} & \multirow[t]{2}{*}{ Compounds } & \multicolumn{3}{|c|}{$\mathrm{AB}(n=15)$} & \multicolumn{3}{|c|}{$\mathrm{GR}(n=30)$} & \multicolumn{3}{|c|}{$\mathrm{SP}(n=19)$} & \multicolumn{3}{|c|}{$\mathrm{SU}(n=16)$} & \multicolumn{3}{|c|}{ lavandin $(n=80)$} \\
\hline & & $\min$ & $\max$ & mean & $\min$ & $\max$ & mean & $\min$ & $\max$ & mean & $\min$ & $\max$ & mean & $\min$ & $\max$ & mean \\
\hline 923 & $\alpha$-Pinene & 0.18 & 0.49 & 0.31 & 0.13 & 0.54 & 0.33 & 0.07 & 0.16 & 0.11 & 0.06 & 0.31 & 0.21 & 0.06 & 0.54 & 0.24 \\
\hline 944 & Camphene & 0.19 & 0.38 & 0.27 & 0.10 & 0.33 & 0.22 & 0.08 & 0.19 & 0.13 & 0.06 & 0.28 & 0.19 & 0.06 & 0.38 & 0.20 \\
\hline 973 & Sabinene & 0.33 & 0.80 & 0.59 & 0.18 & 0.56 & 0.36 & 0.00 & 0.23 & 0.12 & 0.13 & 0.39 & 0.25 & 0.00 & 0.80 & 0.33 \\
\hline 980 & $\beta$-Pinene & 0.19 & 0.59 & 0.35 & 0.11 & 0.51 & 0.31 & 0.00 & 0.11 & 0.04 & 0.00 & 0.36 & 0.15 & 0.00 & 0.59 & 0.21 \\
\hline 985 & 3-Octanone & 0.11 & 0.35 & 0.21 & 0.00 & 0.00 & 0.00 & 0.37 & 1.07 & 0.67 & 0.11 & 1.37 & 0.86 & 0.00 & 1.37 & 0.43 \\
\hline 989 & $\beta$-Myrcene & 0.32 & 0.53 & 0.42 & 0.30 & 0.68 & 0.49 & 0.31 & 0.83 & 0.50 & 0.28 & 0.58 & 0.43 & 0.28 & 0.83 & 0.46 \\
\hline 1012 & Hexyl acetate & 0.09 & 0.25 & 0.16 & 0.07 & 0.22 & 0.13 & 0.17 & 0.82 & 0.41 & 0.00 & 0.13 & 0.04 & 0.00 & 0.82 & 0.18 \\
\hline 1030 & Limonene & 0.55 & 0.85 & 0.68 & 0.41 & 0.84 & 0.63 & 0.00 & 1.08 & 0.64 & 0.40 & 1.18 & 0.88 & 0.00 & 1.18 & 0.71 \\
\hline 1034 & Eucalyptol $^{\mathrm{b}}$ & 6.75 & 10.46 & 8.44 & 3.11 & 7.66 & 5.31 & 2.95 & 4.30 & 3.51 & 2.79 & 10.05 & 7.28 & 2.79 & 10.46 & 6.13 \\
\hline 1044 & trans- $\beta$-Ocimene & 2.25 & 4.16 & 2.90 & 0.16 & 0.45 & 0.29 & 0.97 & 1.96 & 1.52 & 0.42 & 2.65 & 1.66 & 0.16 & 4.16 & 1.59 \\
\hline 1073 & Linalool oxide & 0.10 & 0.18 & 0.13 & 0.09 & 0.18 & 0.12 & 0.07 & 0.20 & 0.11 & 0.10 & 0.16 & 0.13 & 0.07 & 0.20 & 0.12 \\
\hline 1087 & $\alpha$-Terpinolene & 0.31 & 0.45 & 0.36 & 0.28 & 0.41 & 0.35 & 0.20 & 0.34 & 0.25 & 0.23 & 0.41 & 0.34 & 0.20 & 0.45 & 0.32 \\
\hline 1098 & Linalool & 30.67 & 37.60 & 34.69 & 28.44 & 39.55 & 33.79 & 30.07 & 39.31 & 35.54 & 35.40 & 49.54 & 43.33 & 28.44 & 49.54 & 36.84 \\
\hline 1106 & Octen-1-ol acetate & 0.32 & 0.68 & 0.48 & 0.22 & 0.50 & 0.32 & 0.07 & 0.43 & 0.27 & 0.12 & 0.25 & 0.18 & 0.07 & 0.68 & 0.31 \\
\hline 1145 & Hexyl isobutyrate & 0.16 & 0.20 & 0.18 & 0.15 & 0.25 & 0.19 & 0.10 & 0.19 & 0.14 & 0.14 & 0.24 & 0.19 & 0.10 & 0.25 & 0.17 \\
\hline 1150 & Camphor & 8.23 & 10.14 & 9.15 & 5.81 & 8.53 & 6.84 & 3.97 & 5.68 & 4.66 & 3.17 & 7.73 & 5.82 & 3.17 & 10.14 & 6.62 \\
\hline 1168 & Lavandulol & 0.36 & 1.00 & 0.69 & 0.34 & 1.16 & 0.65 & 0.10 & 0.96 & 0.39 & 0.00 & 1.31 & 0.21 & 0.00 & 1.31 & 0.48 \\
\hline 1171 & Borneol & 1.94 & 3.60 & 2.95 & 2.31 & 4.16 & 3.06 & 2.09 & 3.71 & 2.90 & 3.62 & 8.48 & 6.42 & 1.94 & 8.48 & 3.83 \\
\hline 1183 & Terpinen-4-ol & 0.48 & 1.49 & 0.91 & 1.86 & 4.93 & 3.43 & 0.09 & 0.86 & 0.30 & 0.15 & 3.59 & 0.73 & 0.09 & 4.93 & 1.34 \\
\hline 1193 & Hexyl butyrate & 0.30 & 0.55 & 0.39 & 0.30 & 0.55 & 0.41 & 0.43 & 0.92 & 0.69 & 0.31 & 0.71 & 0.51 & 0.30 & 0.92 & 0.50 \\
\hline 1197 & $\alpha$-Terpineol & 0.48 & 0.97 & 0.76 & 0.37 & 1.65 & 0.90 & 0.26 & 1.86 & 0.96 & 0.65 & 1.23 & 0.97 & 0.26 & 1.86 & 0.90 \\
\hline 1260 & Linalyl acetate & 22.80 & 28.56 & 25.55 & 26.94 & 37.33 & 31.27 & 34.71 & 44.09 & 38.03 & 17.34 & 29.72 & 21.96 & 17.34 & 44.09 & 29.20 \\
\hline 1293 & Lavandulyl acetate & 1.40 & 1.81 & 1.55 & 1.56 & 2.95 & 2.36 & 0.84 & 2.10 & 1.47 & 0.19 & 1.85 & 0.58 & 0.19 & 2.95 & 1.49 \\
\hline 1386 & Geranyl acetate & 0.33 & 0.54 & 0.43 & 0.27 & 0.85 & 0.49 & 0.34 & 1.00 & 0.62 & 0.33 & 0.60 & 0.46 & 0.27 & 1.00 & 0.50 \\
\hline 1429 & $\beta$-Caryophyllene & 2.17 & 3.19 & 2.60 & 1.30 & 2.12 & 1.75 & 1.08 & 1.71 & 1.37 & 1.03 & 2.01 & 1.38 & 1.30 & 3.19 & 1.77 \\
\hline 1460 & $\beta$-Farnesene & 0.53 & 1.17 & 0.83 & 1.02 & 1.81 & 1.38 & 0.69 & 1.04 & 0.85 & 0.81 & 1.48 & 1.02 & 0.53 & 1.81 & 1.02 \\
\hline 1492 & Germacren D & 0.51 & 0.94 & 0.72 & 0.54 & 1.02 & 0.74 & 0.46 & 0.70 & 0.56 & 0.38 & 0.83 & 0.53 & 0.38 & 0.94 & 0.64 \\
\hline 1594 & Caryophyllene oxide & 0.08 & 0.19 & 0.12 & 0.00 & 0.13 & 0.08 & 0.05 & 0.12 & 0.08 & 0.00 & 0.14 & 0.07 & 0.00 & 0.19 & 0.09 \\
\hline
\end{tabular}

a $R I$ : Retention indices on HP-5 capillary column.

b cis- $\beta$-ocimene.

To build all PLS regression models (PLS R and PLS-DA R), 91 samples were used: (FI, $n=13$ ), (MA, $n=16$ ), (MT, $n=8)$, (AB, $n=10)$, (GR, $n=20)$, (SU, $n=11)$ and (SP, $n=13$ ) and the internal validation step was performed using full cross-validation. To test the performance of the models, 44 samples were used: (FI, $n=6$ ), (MA, $n=8)$, (MT, $n=4),(\mathrm{AB}, n=10),(\mathrm{GR}, n=10),(\mathrm{SU}, n=5)$ and (SP, $n=6)$.

Choice of the number of factors: The Jack-Knife technique [42] was used to fix the number of factors needed for model construction. Full cross-validation was applied in regression, so that the optimal factor number was determined based on the prediction for the number of left-out samples from the individual model.

Pearson coefficient $(r)$ : Evaluation of the regression coefficient was carried out by computing the Pearson coefficient as follows:

$r=\frac{\operatorname{cov}(X, Y)}{\operatorname{var} X \times \operatorname{var} Y}$

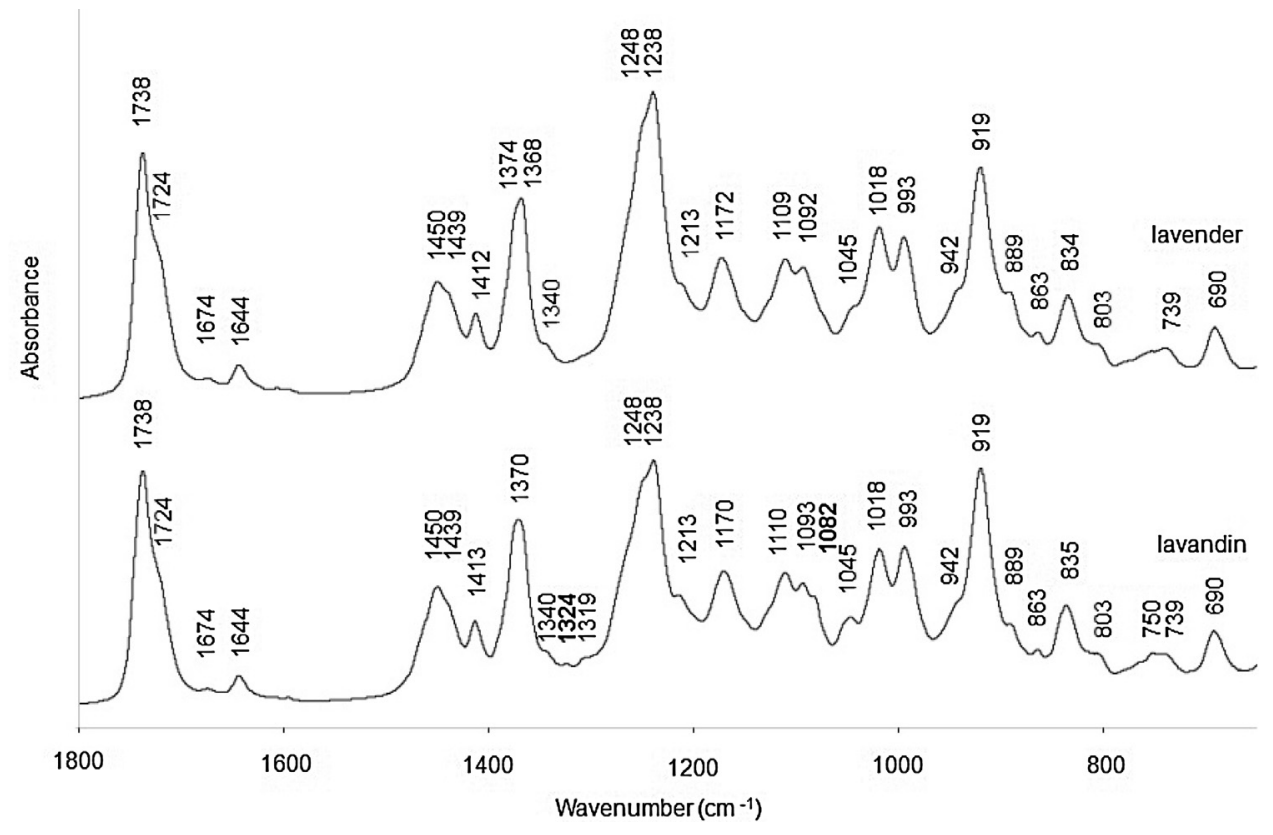

Fig. 1. MIR spectra of lavender (FI) and lavandin (GR) EOs. 
where $\operatorname{cov}(\mathrm{X}, \mathrm{Y})$ is the covariance and var is the variance.

Software: Chemometric analysis of the MIR spectra was performed using a commercial software program (The UNSCRAMBLER X version 10.3 from CAMO/Software, Oslo, Norway).

\section{Results and discussion}

\subsection{Gas chromatography}

The identification of the compounds was achieved by comparing their mass spectra with those in Wiley275 and NIST05a libraries, as well as by comparing their retention indices with those of authentic samples. Tables 1 and 2 list the relative oil composition determined from the areas of the peaks corresponding to the 28 major compounds, each accounting for more than $0.1 \%$ in the EOs. The major compounds identified in lavender essential oils are linalyl acetate (39.31\%), linalool (29.0\%), $\beta$-caryophyllene (4.93\%), eucalyptol (3.81\%), trans- $\beta$-ocimene
(3.76\%) and lavandulyl acetate (3.49\%). Regarding lavender varieties, the low linalool content in MT (20.38\%) and FI $(27.07 \%)$ is characteristic of these varieties as is the high lavandulyl acetate content (4.61\% for MT and 5.14\% for FI). The low eucalyptol content in MA $(1.44 \%)$ is characteristic of this variety. The high trans- $\beta$-ocimene content in MT (7.32\%) is characteristic of this variety. The high 3-octanone content in MA (1.31\%) is characteristic of the MA variety.

The major compounds identified in lavandin EOs are linalool (36.84\%), linalyl acetate (29.20\%), camphor (6.62\%), eucalyptol (6.13\%) and borneol (3.83\%). Regarding lavandin varieties, the low linalyl acetate content in SU (21.96\%) is characteristic of the SU variety, whereas the high eucalyptol content in $A B(8.44 \%)$ is characteristic of the $A B$ variety. As shown in Tables 1 and 2, there are significant differences between the lavender and lavandin EOs, particularly regarding the contents in camphor and $\beta$-caryophyllene. The lower camphor content in lavender $(0.39 \%)$ than in lavandin $(6.62 \%)$ justifies that lavender is used in the perfume

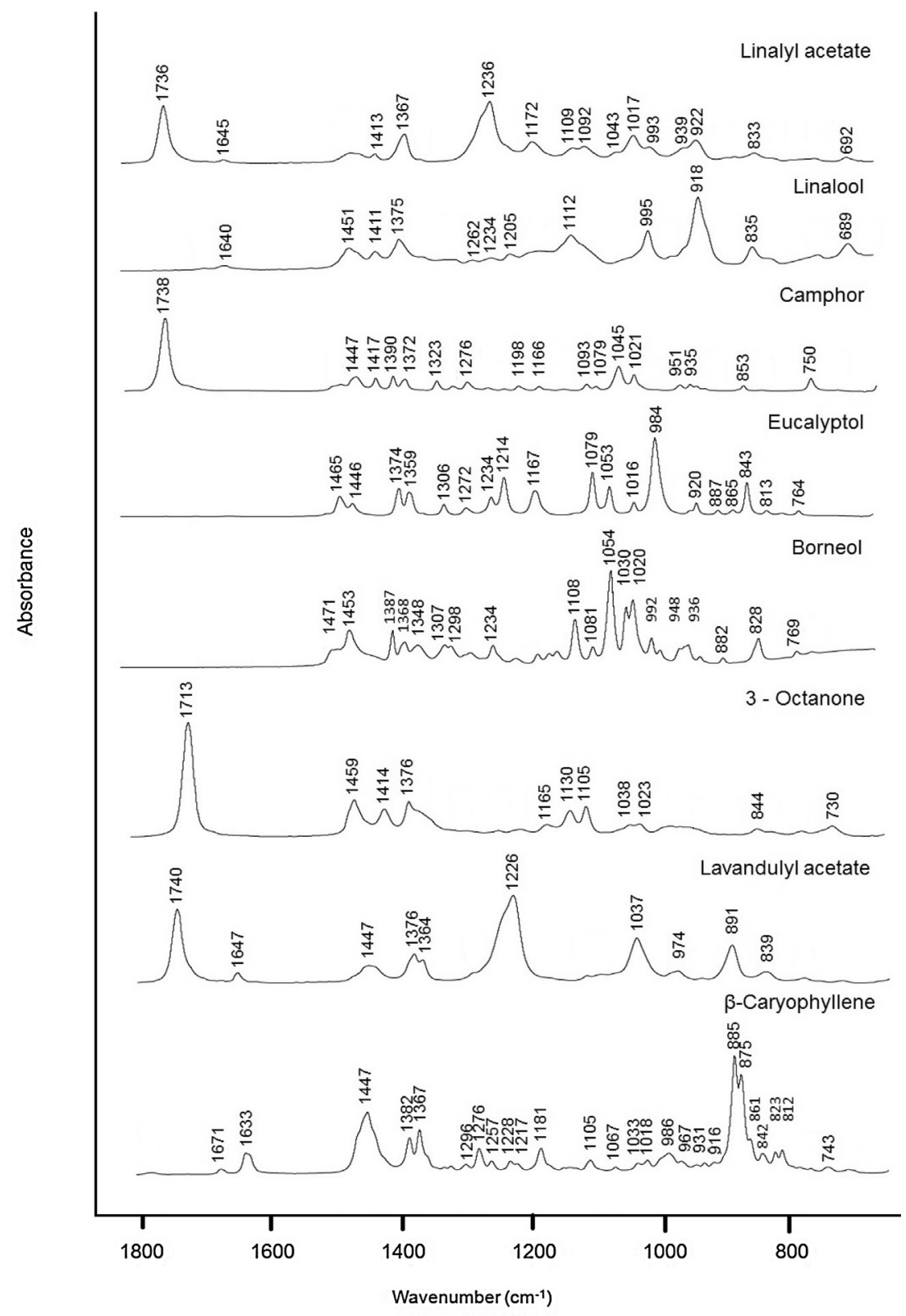

Fig. 2. Pure spectra of the 8 main compounds in lavender and lavandin EOs. 
industry while lavandin is used in the toiletries industry. The high $\beta$-caryophyllene content in lavender (4.93\%) compared to lavandin (1.77\%) is characteristic of lavenders. All these differences show the possibility of discriminating between lavender and lavandin EOs.

\subsection{MIR spectroscopy}

Fig. 1 shows the characteristic MIR spectra of lavender/lavandin EOs in the $1800-650 \mathrm{~cm}^{-1}$ range. Even though the compositions of lavender and lavandin EOs differ largely, their spectra are only slightly different. Two examples can be given: the bands at 1324 and $1082 \mathrm{~cm}^{-1}$, which can be attributed to camphor (1323 and $1079 \mathrm{~cm}^{-1}$ in Fig. 2). The spectra of the eight pure terpenoids at high concentrations in lavender/lavandin EOs were shown in Fig. 2. The assignment of the major bands was carried out using literature data (see Table 3) [43-46]. Lavandulyl acetate, camphor, linalyl acetate and 3-octanone showed a $v_{\mathrm{C}=\mathrm{O}}$ at 1740 , 1738,1736 and $1713 \mathrm{~cm}^{-1}$, respectively. Lavandulyl acetate, linalyl acetate, linalool and $\beta$-caryophyllene showed a $\nu_{\mathrm{C}=\mathrm{C}}$ at 1647,1645 , 1640 and $1633 \mathrm{~cm}^{-1}$, respectively. The weak bands between 1483 and $1412 \mathrm{~cm}^{-1}$ and between 1390 and $1357 \mathrm{~cm}^{-1}$ could be assigned to the $\delta_{\mathrm{CH}}$ of methyl and methylene groups. The absorbance between 1300 and $1000 \mathrm{~cm}^{-1}$ represented the $v_{\mathrm{C}-\mathrm{O}}$ and included bands at 1236, 1172, 1109 and $1017 \mathrm{~cm}^{-1}$ for linalyl acetate and $1226 \mathrm{~cm}^{-1}$ for lavandulyl acetate. The weak bands at 1272, 1167 , 1079,920 and $813 \mathrm{~cm}^{-1}$ were attributed to eucalyptol. The weak bands at $1020 \mathrm{~cm}^{-1}$ and $992 \mathrm{~cm}^{-1}$ for borneol, at $1018 \mathrm{~cm}^{-1}$ for $\beta$-caryophyllene and at 995, 918, 835 and $689 \mathrm{~cm}^{-1}$ for linalool could be assigned to the $\delta_{\mathrm{CH}}$. The $\beta$-caryophyllene spectrum shows $\omega_{\mathrm{CH}}$ at 885 and $861 \mathrm{~cm}^{-1}$.

\subsection{Principal component analysis (PCA)}

Principal Component Analysis on the first and third components PC1 and PC3, which represent $80 \%$ of the total spectral variance, was carried out on MIR data (Figs. 3 and 4). PC2, which represents $16 \%$ of the total spectral variance, does not provide a complete separation between lavender and lavandin groups but intensifies the difference between MA and MT varieties (Fig. 5).

PC3 separates the lavender and lavandin groups, lavender is negatively projected while lavandin is positively projected (Fig. 3). The observation of the third component (Fig. 4) reveals a high positive contribution at $1735 \mathrm{~cm}^{-1}$ and other smaller contributions at $1415,1390,1324,1274,1080$ and $1049 \mathrm{~cm}^{-1}$, which were attributed to camphor according to the spectra of the pure compounds shown in Fig. 2. The bands at $1324 \mathrm{~cm}^{-1}$ and $1082 \mathrm{~cm}^{-1}$ have already been identified in the camphor and lavandin EO spectra (see 3.2). High camphor content is a metabolomic marker of lavandin EOs. The third component also reveals a high negative contribution at $893 \mathrm{~cm}^{-1}$ and other smaller contributions at 1228 and $1105 \mathrm{~cm}^{-1}$ attributed to $\beta$-caryophyllene and correlated with its high concentration in lavender oils (Fig. 4). $\beta$-Caryophyllene is a metabolomic marker of lavender EOs.

Varieties of lavender and lavandin EOs were differentiated on PC1 and PC3 (Fig. 3). On PC1, we note a high positive contribution at 1737 and $1236 \mathrm{~cm}^{-1}$ and other smaller contributions at 1643,1432 ,

Table 3

EOs and their corresponding metabolomic markers, GC references data and the most characteristic IR bands [37-40].

\begin{tabular}{|c|c|c|c|c|c|c|}
\hline $\begin{array}{l}\text { EOs and metabolomic markers mass } \\
\text { fraction in\% GC }\end{array}$ & $\begin{array}{l}\text { Metabolomic } \\
\text { markers }\end{array}$ & $\begin{array}{l}\text { Mean mass fraction in\% in } \\
\text { lavender EOs }\end{array}$ & $\begin{array}{l}\text { Mean mass fraction } \\
\text { in\% in } \\
\text { lavandin EOs }\end{array}$ & $\begin{array}{l}\text { Mean mass fraction } \\
\text { in\% in } \\
\text { all EOs }\end{array}$ & $\begin{array}{l}\text { Wavenumbers } \\
\left(\mathrm{cm}^{-1}\right)\end{array}$ & Assignment \\
\hline MA (1.31) & 3-Octanone & 0.82 & 0.43 & 0.62 & 1713 & $v(\mathrm{C}=\mathrm{O})$ \\
\hline MA (1.44) & Eucalyptol & $3.8^{\mathrm{a}}$ & $6.13^{\mathrm{a}}$ & $4.97^{\mathrm{a}}$ & 1374 & $\delta\left(\mathrm{CH}_{3}(\mathrm{CO})\right)$ \\
\hline \multirow[t]{8}{*}{$\mathrm{AB}(8.44)$} & & & & & 1272 & $v(\mathrm{C}-\mathrm{O})$ \\
\hline & & & & & 1214 & $v(\mathrm{C}-\mathrm{O}-\mathrm{C})$ \\
\hline & & & & & 1167 & $v(\mathrm{C}-\mathrm{O}-\mathrm{C})$ \\
\hline & & & & & 1079 & $v(\mathrm{C}-\mathrm{O}-\mathrm{C})$ \\
\hline & & & & & 984 & $\omega\left(\mathrm{CH}_{2}\right)$ \\
\hline & & & & & 920 & $\delta(\mathrm{CH})$ \\
\hline & & & & & 843 & $\omega(\mathrm{CH})$ \\
\hline & & & & & 813 & $\delta(\mathrm{CH})$ \\
\hline MT (7.32) & $\begin{array}{l}\text { trans- } \\
\beta \text {-Ocimene }\end{array}$ & 3.76 & 1.59 & 2.67 & & \\
\hline FI (27.07) & Linalool & 29.00 & 36.84 & 32.92 & 1640 & $v(\mathrm{C}=\mathrm{C})$ \\
\hline \multirow[t]{4}{*}{ MT (20.38) } & & & & & 995 & $\delta(\mathrm{CH})$ \\
\hline & & & & & 918 & $\delta(\mathrm{CH})$ \\
\hline & & & & & 835 & $\delta(\mathrm{CH})$ \\
\hline & & & & & 689 & $\delta(\mathrm{CH})$ \\
\hline \multirow[t]{3}{*}{ Lavandin (6.62) } & Camphor & 0.39 & 6.62 & 3.50 & 1738 & $v(\mathrm{C}=\mathrm{O})$ \\
\hline & Borneol & 1.24 & 3.83 & 2.53 & 1020 & $\delta(\mathrm{CH})$ \\
\hline & & & & & 992 & $\delta(\mathrm{CH})$ \\
\hline \multirow[t]{6}{*}{ SU (21.96) } & Linalyl acetate & 39.31 & 29.20 & 34.25 & 1736 & $v(\mathrm{C}=\mathrm{O})$ \\
\hline & & & & & 1645 & $v(\mathrm{C}=\mathrm{C})$ \\
\hline & & & & & 1236 & $v(\mathrm{C}-\mathrm{O})$ \\
\hline & & & & & 1172 & $v(\mathrm{C}-\mathrm{O})$ \\
\hline & & & & & 1109 & $v(\mathrm{C}-\mathrm{O})$ \\
\hline & & & & & 1017 & $v(\mathrm{C}-\mathrm{O})$ \\
\hline \multirow{3}{*}{$\begin{array}{l}\text { FI }(4.61) \\
\quad \operatorname{MT}(5.14)\end{array}$} & Lavandulyl & 3.49 & 1.49 & 2.49 & 1740 & $v(\mathrm{C}=\mathrm{O})$ \\
\hline & acetate & & & & 1647 & $v(\mathrm{C}=\mathrm{C})$ \\
\hline & & & & & 1226 & $v(\mathrm{C}-\mathrm{O})$ \\
\hline \multirow[t]{6}{*}{ Lavender (4.93) } & $\beta$-caryophyllene & 4.93 & 1.77 & 3.35 & 1633 & $v(\mathrm{C}=\mathrm{C})$ \\
\hline & & & & & 1447 & $\delta(\mathrm{CH})$ \\
\hline & & & & & 1367 & $\delta\left(\mathrm{CH}_{3}\right)$ \\
\hline & & & & & 1018 & $\delta(\mathrm{CH})$ \\
\hline & & & & & 885 & $\omega(\mathrm{CH})$ \\
\hline & & & & & 861 & $\omega(\mathrm{CH})$ \\
\hline
\end{tabular}

\footnotetext{
a cis- $\beta$-ocimene. vibrations $\nu$ : streching; $\delta$ : deformation and $\omega$ : wagging.
} 


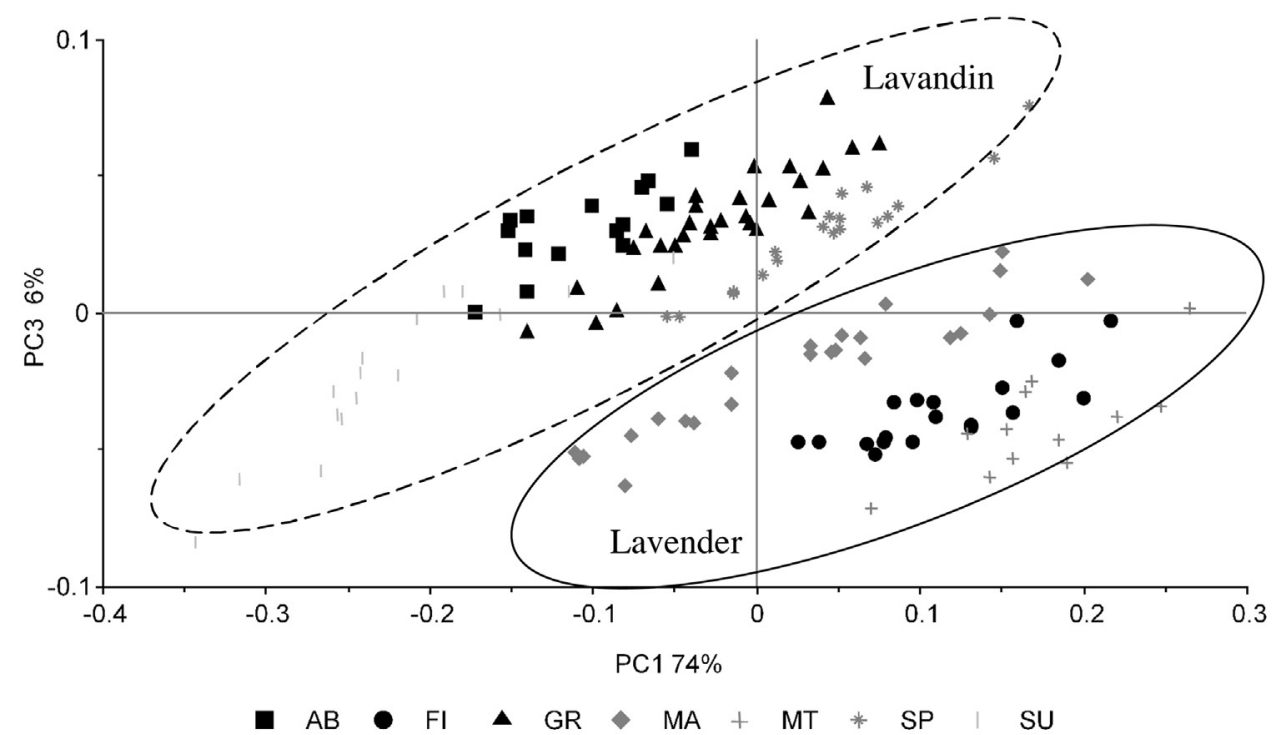

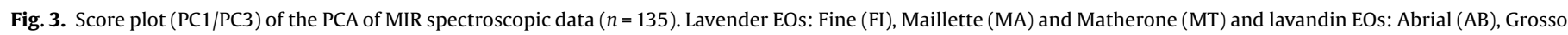
(GR), Super (SP) and Sumian (SU).
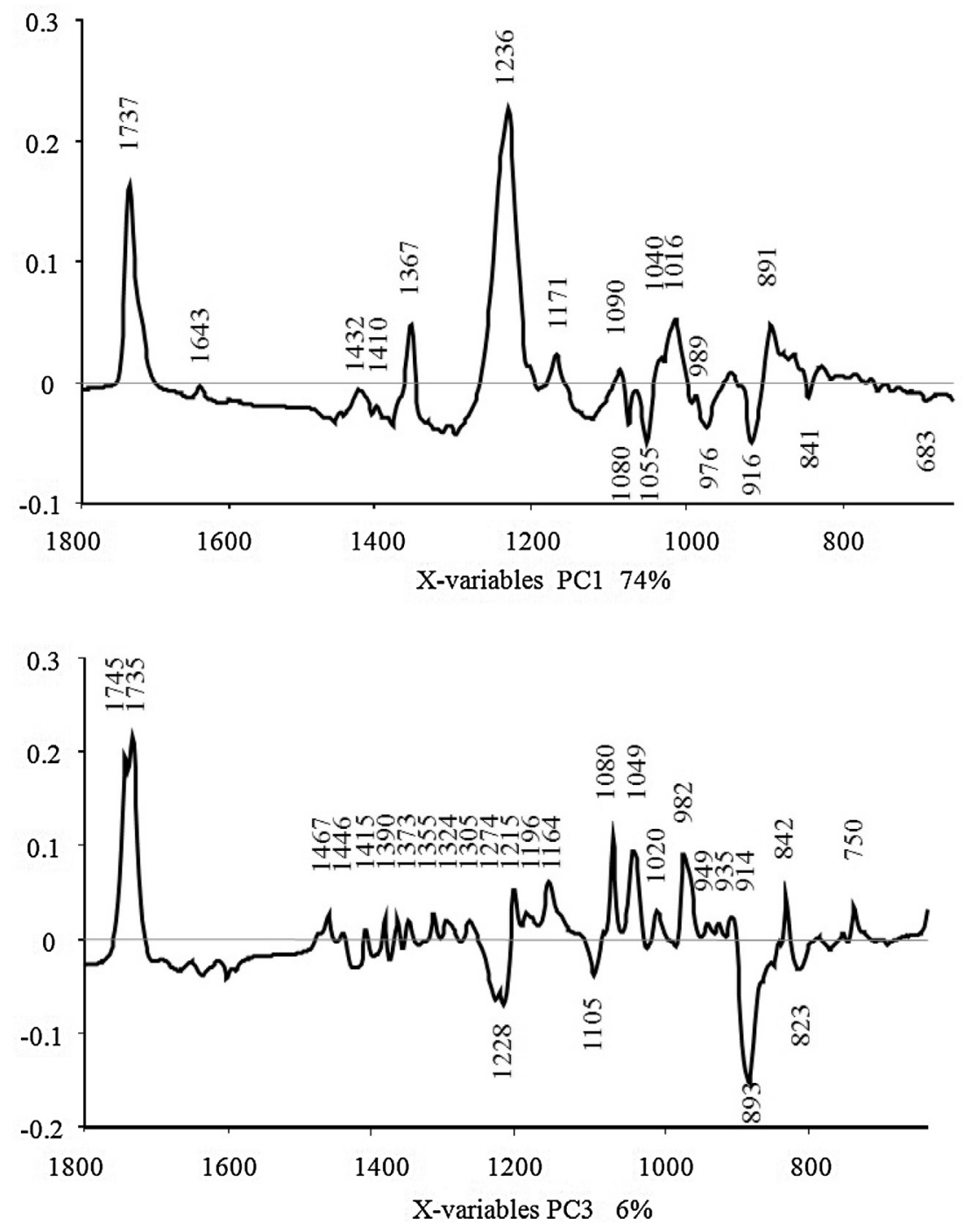

Fig. 4. Loading plots (PC1/PC3) of the PCA of MIR data. 


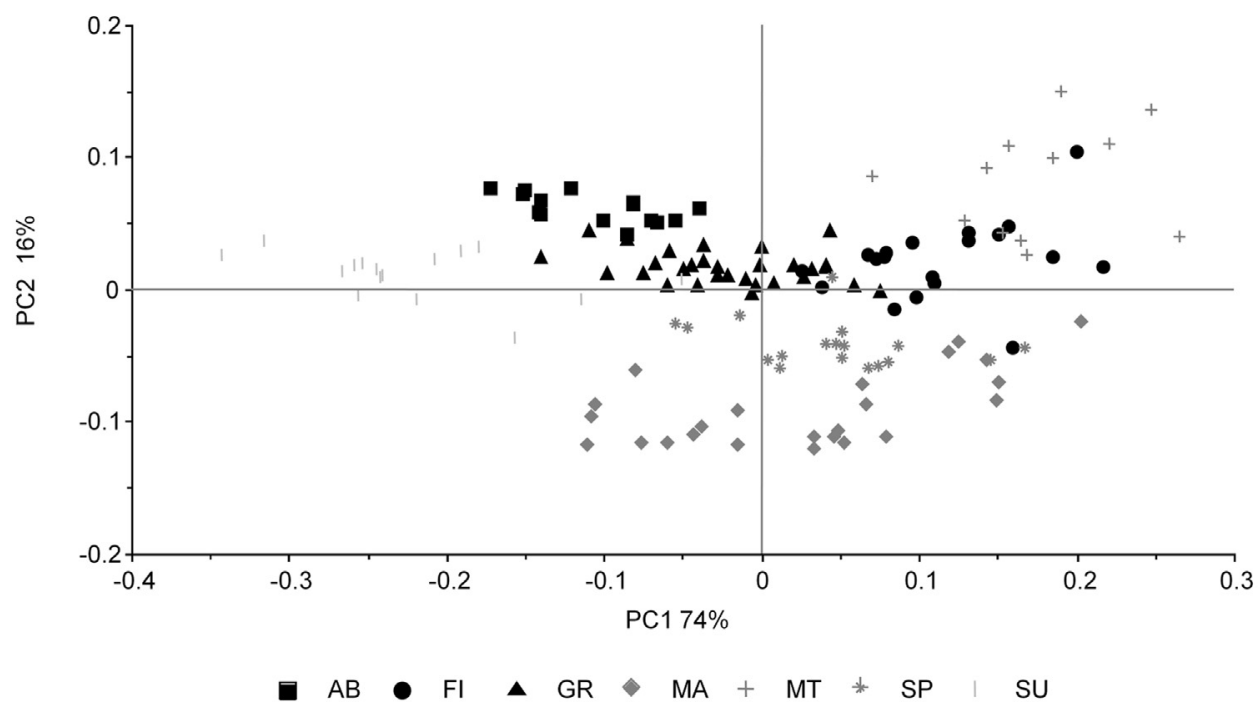

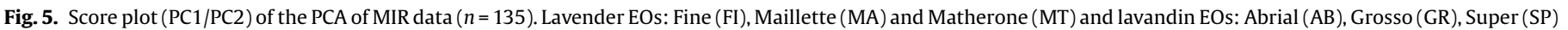
and Sumian (SU).

$1367,1040 \mathrm{~cm}^{-1}$ attributed to linalyl acetate and lavandulyl acetate (Figs. 2 and 4). The bands at 1410,1171, 1090, 1016, $989 \mathrm{~cm}^{-1}$ are characteristic of linalyl acetate, while the band at $891 \mathrm{~cm}^{-1}$ is characteristic of lavandulyl acetate. These bands are correlated with the higher lavandulyl acetate concentration in the FI and MT varieties and are anti-correlated with the lower linalyl acetate concentration in the SU variety. Linalyl acetate is a metabolomic marker of the SU variety and lavandulyl acetate is a metabolomic marker of the FI and MT varieties. We note the presence of small negative contributions at 1080,1055, 976, 916 and $841 \mathrm{~cm}^{-1}$ attributed to eucalyptol. These bands are correlated with the higher concentration of eucalyptol in the $A B$ varieties. Eucalyptol is a metabolomic marker of the $A B$ variety. We also observe the presence of other small negative contributions at 916 and $683 \mathrm{~cm}^{-1}$ attributed to linalool. These bands are correlated with the lower concentration of linalool in the FI and MT varieties. Linalool is a metabolomic marker of the FI and MT varieties.

On PC3, we note a high positive contribution at 1164, 1080 and $1049 \mathrm{~cm}^{-1}$ and other smaller contributions at 1467, 1446, 1373, 1274 and $1020 \mathrm{~cm}^{-1}$ attributed both to camphor and eucalyptol.
The bands at 1745, 1735, 1415, 1390, 1324, 1196, 949, 935, 914 and $750 \mathrm{~cm}^{-1}$ are characteristic of camphor, which is the metabolomic marker of lavandin EOs while the bands at 1355, 1305, 1215, 982 and $842 \mathrm{~cm}^{-1}$ are characteristic of eucalyptol. The bands characteristic of eucalyptol are correlated with the higher eucalyptol concentration in the $A B$ variety. To provide a separation between $\mathrm{AB}$ and other varieties, PC1 and $\mathrm{PC} 3$ use the same metabolomic marker. We also note a high negative contribution at $1228 \mathrm{~cm}^{-1}$ attributed to both lavandulyl acetate and $\beta$-caryophyllene. The band found at $893 \mathrm{~cm}^{-1}$ is characteristic of lavandulyl acetate while the bands at 1105 and $823 \mathrm{~cm}^{-1}$ are characteristic of $\beta$-caryophyllene, which is the metabolomic marker of lavender EOs. Lavandulyl acetate is in higher concentration in the FI and MT varieties. We confirm that lavandulyl acetate is a metabolomic marker of the FI and MT varieties.

On PC2 we note a high positive contribution at $1742 \mathrm{~cm}^{-1}$ and $889 \mathrm{~cm}^{-1}$ and other smaller contributions at 1646, 1444, 1226, 844 and $789 \mathrm{~cm}^{-1}$ attributed to lavandulyl acetate (Fig. 6). These bands are correlated with a higher lavandulyl acetate concentration in the MT variety. Lavandulyl acetate is a metabolomic marker

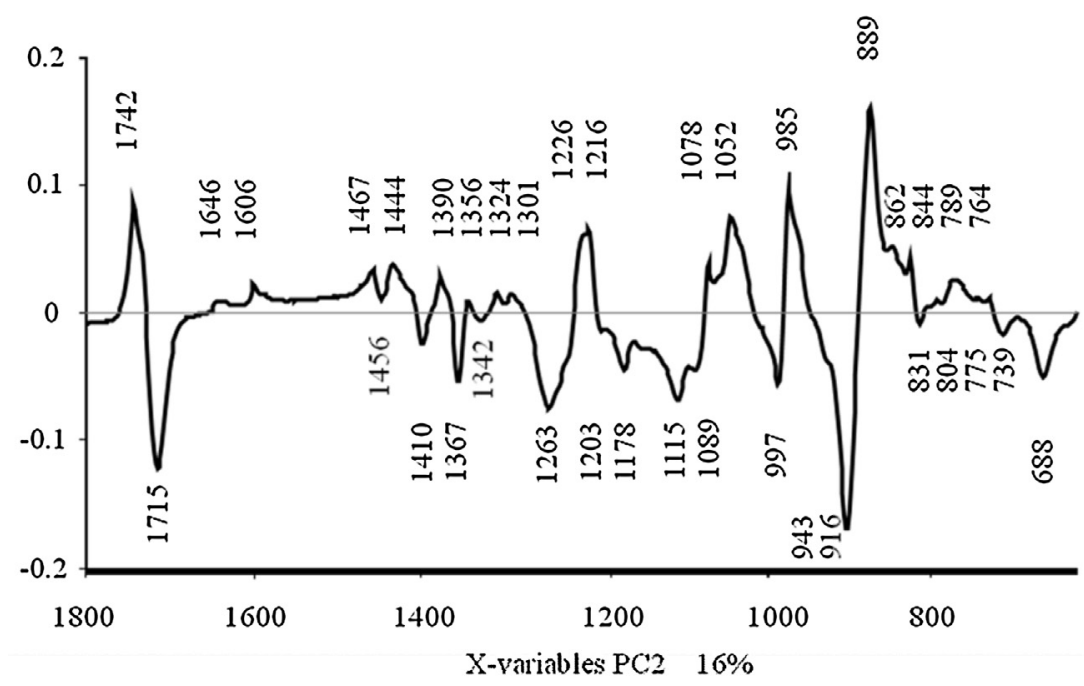

Fig. 6. Loading plot (PC2) of the PCA of MIR data. 
Table 4

Classification matrix obtained in prediction (PLS-DA regression) of lavender and lavandin EO varieties established from MIR data.

\begin{tabular}{|c|c|c|c|c|c|c|c|c|c|c|c|c|}
\hline EOs & & Variety & $\begin{array}{l}\text { Number of latent } \\
\text { variables }\end{array}$ & $\begin{array}{l}\mathrm{AB} \\
(n=5)\end{array}$ & $\begin{array}{l}\text { GR }(n \\
=10)\end{array}$ & $\begin{array}{l}\text { SP } \\
(n=6)\end{array}$ & $\begin{array}{l}\text { SU } \\
(n=5)\end{array}$ & $\begin{array}{l}\text { FI } \\
(n=6)\end{array}$ & $\begin{array}{l}\text { MA } \\
(n=8)\end{array}$ & $\begin{array}{l}\text { MT } \\
(n=4)\end{array}$ & $\begin{array}{l}\text { False negative } \\
\text { samples }\end{array}$ & $\begin{array}{l}\text { False positive } \\
\text { samples }\end{array}$ \\
\hline \multirow{7}{*}{$\begin{array}{l}\text { MIR } \\
\text { models }\end{array}$} & lavandin & $\mathrm{AB}$ & 14 & 5 & 0 & 0 & 0 & 0 & 0 & 0 & 0 & 0 \\
\hline & & GR & 15 & 0 & 10 & 0 & 1 & 0 & 0 & 0 & 0 & 1 \\
\hline & & SP & 14 & 0 & 0 & 6 & 0 & 0 & 0 & 0 & 0 & 0 \\
\hline & & SU & 7 & 0 & 0 & 0 & 4 & 0 & 0 & 0 & 1 & 0 \\
\hline & lavender & FI & 13 & 0 & 0 & 0 & 0 & 6 & 0 & 1 & 0 & 1 \\
\hline & & MA & 11 & 0 & 0 & 0 & 0 & 0 & 7 & 0 & 1 & 0 \\
\hline & & MT & 10 & 0 & 0 & 0 & 0 & 0 & 0 & 3 & 1 & 0 \\
\hline
\end{tabular}

of the MT variety. We note a high positive contribution at $889 \mathrm{~cm}^{-1}$ and other smaller contributions at 1467, 1444, 1390, 1356, 1301, $1216,1078,1052,985,862,844,789$ and $764 \mathrm{~cm}^{-1}$ attributed to eucalyptol. These bands are correlated with a lower eucalyptol concentration in the MA variety. Eucalyptol is a metabolomic marker of the MA variety. We also note a high negative contribution at $1715 \mathrm{~cm}^{-1}$ and other smaller at 1456,1410 , 1367 and $1203 \mathrm{~cm}^{-1}$ attributed to 3-octanone. These bands are correlated with a higher 3-octanone concentration in the MA variety. 3-Octanone is a metabolomic marker of the MA variety. We also note a high negative contribution at $916 \mathrm{~cm}^{-1}$ and other smaller contributions at 1456, 1410, 1367, 1342, 1263, 1203, 1115, $997,831,804,739$ and $688 \mathrm{~cm}^{-1}$ attributed to linalool. These bands are correlated with a lower linalool concentration in the MT variety. Linalool is a metabolomic marker of the MT variety.

\subsection{Partial least square regression (PLS-DA $r$ and PLS R)}

The geographic origins of the samples were determined using PLS-DA regression. Table 4 gives the prediction results for the recognition of the origins of 44 lavender/lavandin EO samples. In a first step, the discrimination between the lavender and lavandin EOs was tested. The results were excellent with a $100 \%$ correct classification. Then in a second step, the seven varieties were discriminated and well-predicted with a percentage of correct classification between 98 and 100\%, as shown in Table 4 . Classification was 100\% correct for the $A B$ and SP varieties. Concerning lavender varieties, there was one false positive sample of the FI variety, one false negative sample for the MA variety as well as for the MT variety. For the SU variety, there was one falsenegative. MIR spectroscopy was used as a recognition method. As it is possible to classify samples depending on whether they are samples of lavender/lavandin EOs and their varieties, it is interesting to understand how these classifications are established.

The determination of essential oil compositions by chemometric analysis of MIR data was achieved using PLS regression algorithms. The reference data were gas chromatographic data. Table 5 gives the statistics of the PLS regression models for the 14 quantified compounds (accounting for more than $0.4 \%$ ). For best results, all the PLS regression models were built from EMSC pretreated data.

As shown in Table 5, compounds can be classified into four groups according to their relative error of prediction (REP). In the first group, very good results were obtained compounds present at high concentrations such as linalool, linalyl acetate (Fig. 7) and camphor $(\mathrm{REP} \leq 5 \%)$. In the second group, four compounds were correctly predicted since their relative error of prediction was between 5 and 10\%: eucalyptol, $\alpha$-terpineol, lavandulyl acetate and $\beta$-caryophyllene. In the third group, six compounds were correctly predicted since their relative error of prediction was between 10 and 15\%: 3-octanone, trans- $\beta$-ocimene, borneol, lavandulol, terpinen-4-ol and $\beta$-farnesene. In the last group, a very bad result was obtained for limonene, whose content is the lowest. The performance of the PLS prediction models was directly related to the compound contents.

As Haaland and Thomas explained, the first coefficient of regression (noted vector $\mathrm{B}$ ) was a good approximation of the pure compound spectrum [47] in the case of PLS regression. Thus, the

Table 5

Statistics of the PLS regression models for the 14 main compounds in the lavender and lavandin EOs established from MIR data.

\begin{tabular}{|c|c|c|c|c|c|c|c|c|}
\hline Compounds & $R I^{\mathrm{a}}$ & $\begin{array}{l}\text { Lavender/Lavandin } \\
\text { (Mean mass fraction in\%) }\end{array}$ & $R^{2}$ & SEC & $L V$ & $Q^{2}$ & SEP & $R E P(\%)$ \\
\hline Linalool & 1098 & 32.92 & 0.99 & 0.915 & 2 & 0.99 & 0.824 & 2.50 \\
\hline Linalyl acetate & 1260 & 34.25 & 0.99 & 0.858 & 4 & 0.99 & 0.732 & 2.14 \\
\hline Camphor & 1150 & 3.50 & 0.99 & 0.129 & 9 & 0.99 & 0.184 & 5.26 \\
\hline Eucalyptol $^{\mathrm{b}}$ & 1034 & 4.97 & 0.98 & 0.461 & 6 & 0.99 & 0.376 & 7.56 \\
\hline$\alpha$-Terpineol & 1197 & 0.82 & 0.99 & 0.049 & 16 & 0.98 & 0.072 & 8.78 \\
\hline Lavandulyl acetate & 1293 & 2.49 & 0.99 & 0.214 & 7 & 0.99 & 0.202 & 8.11 \\
\hline$\beta$-Caryophyllene & 1429 & 3.35 & 0.99 & 0.276 & 10 & 0.98 & 0.295 & 8.80 \\
\hline 3-Octanone & 985 & 0.62 & 0.99 & 0.066 & 11 & 0.99 & 0.087 & 14.03 \\
\hline trans- $\beta$-Ocimene & 1044 & 2.67 & 0.99 & 0.240 & 11 & 0.98 & 0.342 & 12.81 \\
\hline Lavandulol & 1168 & 0.70 & 0.99 & 0.071 & 16 & 0.99 & 0.099 & 14.14 \\
\hline Borneol & 1171 & 2.53 & 0.99 & 0.263 & 7 & 0.99 & 0.270 & 10.67 \\
\hline Terpinen-4-ol & 1183 & 1.72 & 0.99 & 0.154 & 11 & 0.99 & 0.217 & 12.61 \\
\hline$\beta$-Farnesene & 1460 & 1.59 & 0.99 & 0.111 & 16 & 0.95 & 0.201 & 12.64 \\
\hline Limonene & 1030 & 0.44 & 0.87 & 0.153 & 5 & 0.86 & 0.154 & 35.00 \\
\hline
\end{tabular}

a RI: Retention indices on HP-5 capillary column.

b cis- $\beta$-ocimene. Prediction model (PLS regression) established from EMSC pretreated MIR data. $R^{2}$ : Coefficients correlation in calibration, $Q^{2}$ : Coefficients correlation in prediction, SEC: Standard error of calibration, SEP: Standard error or prediction, LV: Latent variables and REP: Relative error of prediction. 


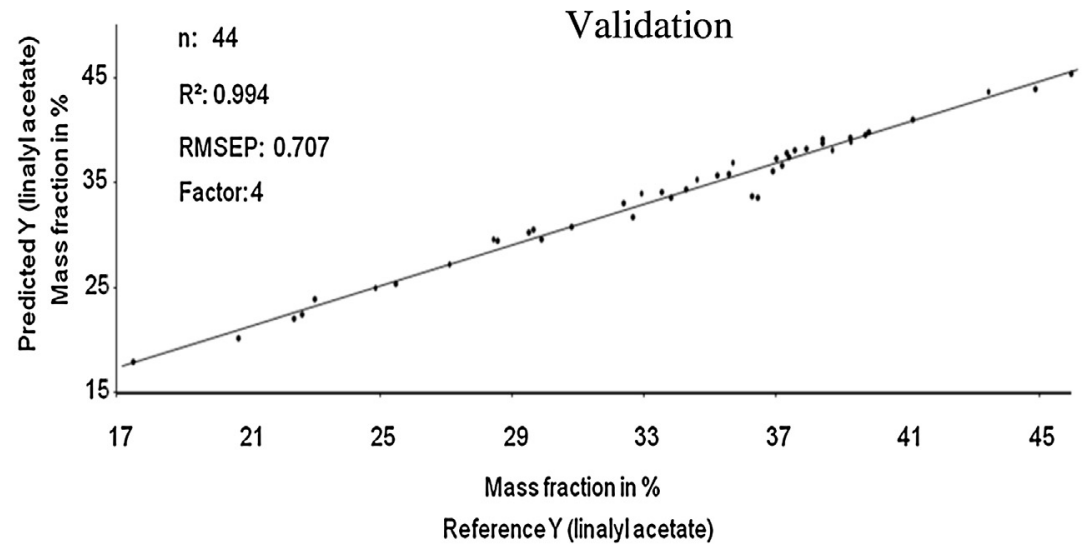

RMSEP: Root Mean Squared Error of Prediction

Fig. 7. Linalyl acetate PLS validation results.

first coefficients of regression obtained for quantification of individual compounds were an approximation of the original feature of the lavender/lavandin EOs and their varieties. For spectroscopists, those regression coefficients B were very useful to discriminate between metabolomic markers of lavender and lavandin essential oils. The B-coefficients obtained for the lavender and lavandin EOs (varieties) and those obtained for the quantitative analysis were compared. Fig. 8 presents the superposition of the B-coefficients obtained for the MT variety and its corresponding metabolomic marker (trans- $\beta$-ocimene). The MT B-coefficients presents high similarities and is correlated with that obtained for trans- $\beta$-ocimene quantitative analysis, with a Pearson coefficient of 0.99 . This high positive value shows that the MT variety was characterized by a high amount of trans- $\beta$-ocimene: a mean content of $7.32 \%$. This high content could be considered as a metabolomic marker of the variety. Fig. 9 presents the superposition of the B-coefficients obtained for the SU variety and its corresponding metabolomic marker (linalyl acetate). The SU B-coefficients present high similarities and are anti-correlated with the regression coefficient obtained for linalyl acetate quantitative analysis, with a Pearson coefficient of -0.98 . The SU variety presented a mean content in linalyl acetate of $21.96 \%$.

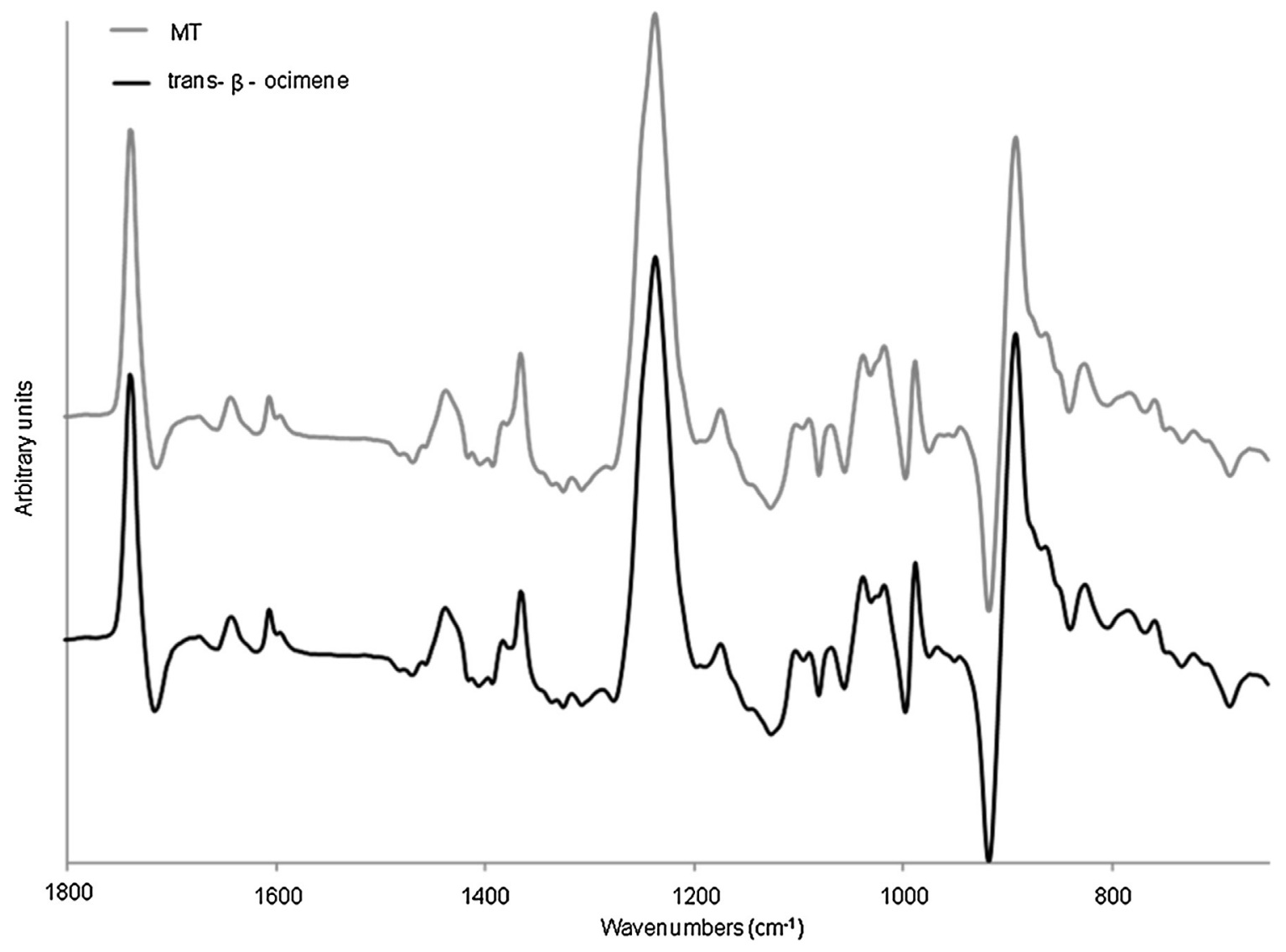

Fig. 8. Superposition of the first regression vectors obtained for MT and trans- $\beta$-ocimene. 


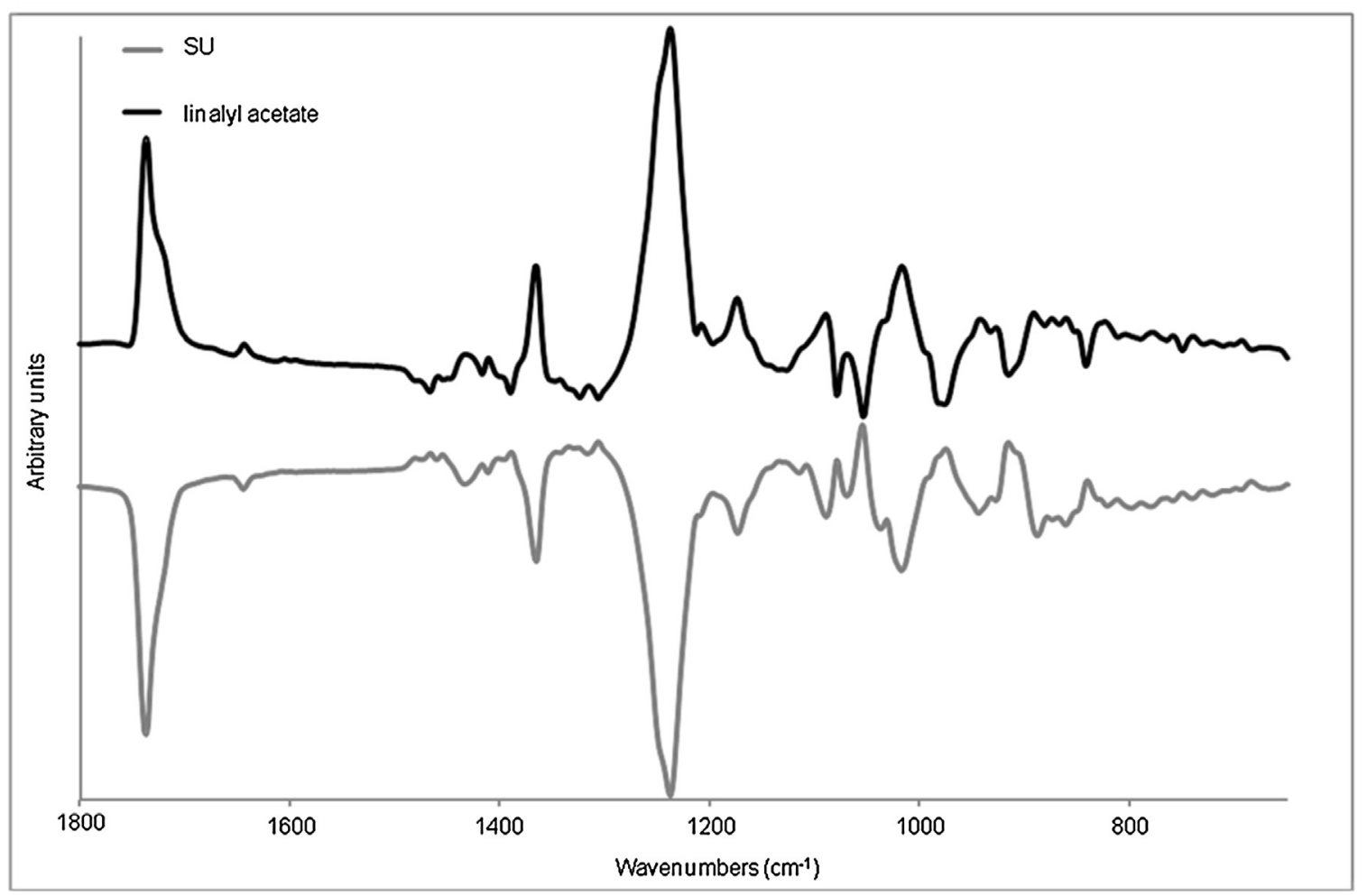

Fig. 9. Superposition of the first regression vectors obtained for SU and linalyl acetate.

This low amount could be considered as a metabolomic marker of the variety. No metabolomic markers were found for the FI, GR and SP varieties.

\subsection{Comparison of MIR and raman spectroscopy}

In a previously published work [31], 104 samples, including 62 lavandin oil samples and 42 lavender oil samples, had been analyzed by Raman spectroscopy. The results are slightly different from the present results, because only two harvested crops were used for Raman analysis. MIR quantification is better than Raman spectroscopy quantification except for terpinen-4-ol. Raman and MIR spectroscopies combined with chemometric analysis were used to discriminate between the lavender/lavandin EOs studied and their varieties (AB, GR, SU, SP, FI, MA and MT). Prediction with MIR is better than with Raman spectroscopy (100\% for lavaender EOs as well as for lavandin EOs, and between $98-100 \%$ and $91-$ $100 \%$ for varieties respectively). Metabolomic markers could be identified upon examination of the B-coefficients (for four varieties with MIR data and five varieties with Raman data). Raman and MIR spectroscopies confirm that eucalyptol is a metabolomic marker for the $A B$ and MA varieties. Raman spectroscopy reveals that lavandulyl acetate, linalool and lavandulol are metabolomic markers for FI, MT and SP, respectively, whereas MIR spectroscopy reveals that trans- $\beta$-ocimene and linalyl acetate are metabolomic markers for the MT and SU varieties, respectively. The band corresponding to the trans- $\beta$-ocimene $\mathrm{C}=\mathrm{C}$ bond is more intensive in MIR than in Raman spectra. For this reason, trans- $\beta$-ocimene can be detected as a metabolomic marker by MIR spectroscopy. No metabolomic marker was found for the SU variety with Raman spectroscopy, and no metabolomic markers were found for the FI and SP varieties with MIR spectroscopy. Furthermore, these two methods did not reveal any metabolomic marker for the GR variety.

\section{Conclusion}

Mid-infrared spectroscopy combined with chemometric analysis was used to quantify the main compounds in lavender and lavandin EOs. The results quite accurately matched the prediction for compounds present at high concentrations, but much less so for minor compounds. Yet camphor, although minor, which may serve to detect adulteration, is correctly predicted. In addition, MIR spectroscopy combined with chemometric analysis was used to discriminate the studied EOs (lavender and lavandin) and their varieties (Abrial, Grosso, Sumian, Super, Fine, Maillette and Matherone). The lavender/lavandin EOs and their varieties were very well predicted (100\% for lavender/lavandin EOs and between 98 and $100 \%$ for varieties). Metabolomic markers could be identified through PCA (for lavender/lavandin EOs and varieties) and using examination of first regression B-coefficients (for four varieties). Mid-infrared spectroscopy or/and Raman spectroscopy associated with chemometric analysis thus demonstrated to be a powerful tool for the assessment of the lavender authenticity. This approach could be applied to other essential oils commonly used in the perfume industry, in medicine as well as in other fields.

\section{Acknowledgements}

The authors are grateful to the "Société Coopérative Parfums Provence Ventoux", for providing samples of lavender and lavandin essential oils.

\section{Appendix A. Supplementary data}

Supplementary data associated with this article (Figs. S1-S4) can be found, in the online version, at http://dx.doi.org/10.1016/j. vibspec.2016.04.004. 


\section{References}

[1] E.A. Weiss, Essential Oil Crops, CAB International, 1997.

[2] M. Lis-Balchin, Lavender - The Genus Lavandula, CRC Press, 2003.

[3] K.H.C. Baser, G. Buchbauer, Handbook of Essential Oils - Science, Technology and Applications, CRC Press, 2009.

[4] B. Adorjan, G. Buchbauer, Flavour Fragr. J. 25 (2010) 407-426.

[5] H.M.A. Cavanagh, J.M. Wilkinson, Healthc. Infect. 10 (2005) 35-37.

[6] H.M.A. Cavanagh, J.M. Wilkinson, Phytother. Res. 16 (2002) 301-308.

[7] A. González-Coloma, F. Delgado, J.M. Rodilla, L. Silva, J. Sanz, J. Burillo, Biochem. Syst. Ecol. 39 (2011) 1-8.

[8] P. Costa, S. Gonçalves, P. Valentão, P.B. Andrade, C. Almeida, J.M.F. Nogueira, A. Romano, Food Chem. 141 (2013) 2501-2506.

[9] S.M. Da Silveira Jr., A. Cunha, G.N. Scheuermann, F.L. Secchi, S. Verruck, M. Krohn, C.R.W. Vieira, Rev. Inst. Adolfo Lutz 71 (2012) 471-480.

[10] H. Song, C. Yang, Z. Zhang, Gas chromatography-mass spectrum/olfactometry (GC O-MS) assisted preparation method for strengthened thermal response savory flavoring, Patent CN201110131527, 2011.

[11] S. Maietti, D. Rossi, A. Guerrini, C. Useli, C. Romagnoli, F. Poli, R. Bruni, G. Sacchetti, Flavour Fragr. J. 28 (2013) 144-154.

[12] I. Bombarda, N. Dupuy, J.-P. Levanda, E.M. Gaydou, Anal. Chim. Acta 613 (2008) 31-39.

[13] F. Mehl, G. Marti, J. Boccard, B. Debrus, P. Merle, E. Delort, L. Baroux, V. Raymo, M.I. Velazco, H. Sommer, J.-L. Wolfender, S. Rudaz, Food Chem. 143 (2014) 325335.

[14] S.Y. Tankeu, I. Vermaak, G.P.P. Kamatou, A.M. Viljoen, Ind. Crops Prod. 59 (2014) 234-240.

[15] N. Dupuy, V. Gaydou, J. Kister, Am. J. Anal. Chem. 5 (2014) 633-645.

[16] T. Mavimbela, A. Viljoen, I. Vermaak, J. Appl. Res. Med. Aromat. Plants 1 (2014) e8-e14.

[17] M. Sandasi, G.P.P. Kamatou, M. Baranska, A.M. Viljoen, South Afr. J. Bot. 76 (2010) 692-700.

[18] H. Schulz, B. Schrader, R. Quilitzsch, B. Steuer, Appl. Spectrosc. 56 (2002) 117 124.

[19] H. Schulz, B. Schrader, R. Quilitzsch, S. Pfeffer, H. Krüger, J. Agric. Food Chem. 51 (2003) 2475-2481.

[20] A. Smelcerovic, A. Djordjevic, J. Lazarevic, G. Stojanovic, Curr. Anal. Chem. 9 (2013) 61-70.

[21] T.K.T. Do, F. Hadji-Minaglou, S. Antoniotti, X. Fernandez, TrAC Trends Anal. Chem. 66 (2015) 146-157.
[22] D. Cozzolino, Planta Med. 75 (2009) 746-756.

[23] O. Galtier, Y. Le Dréau, D. Ollivier, J. Kister, J. Artaud, N. Dupuy, Appl. Spectrosc. 62 (2008) 583-590.

[24] N. Dupuy, O. Galtier, Y. Le Dréau, C. Pinatel, J. Kister, J. Artaud, Eur. J. Lipid Sci. Technol. 112 (2010) 463-475.

[25] Y.W. Lai, E.K. Kemsley, R.H. Wilson, J. Agric. Food Chem. 42 (1994) 1154-1159.

[26] H.S. Tapp, M. Defernez, E.K. Kemsley, J. Agric. Food Chem. 51 (2003) 6110-6115.

[27] S. Yudthavorasit, K. Wongravee, N. Leepipatpiboon, Food Chem. 158 (2014) $101-111$.

[28] Y. Li, D. Kong, H. Wu, Ind. Crops Prod. 41 (2013) 269-278.

[29] M. Wang, B. Avula, Y.-H. Wang, J. Zhao, C. Avonto, J.F. Parcher, V. Raman, J.A Zweigenbaum, P.L. Wylie, I.A. Khan, Food Chem. 152 (2014) 391-398.

[30] C.A. Nunes, Food Res. Int. 60 (2014) 255-261.

[31] S. Lafhal, P. Vanloot, I. Bombarda, R. Valls, J. Kister, N. Dupuy, J. Raman Spectrosc. 46 (2015) 577-585.

[32] N.K. Afseth, A. Köhler Chemom. Intell. Lab. Syst 117 (2012) 92-99.

[33] S. Wold, K. Esbensen, P. Geladi, Chemom. Intell. Lab. Syst. 2 (1987) 37-52.

[34] S. Millar, P. Robert, M.F. Devaux, R.C.E. Guy, P. Maris, Appl. Spectrosc. 9 (1996) 1134-1139.

[35] M. Sjöström, S. Wold, W. Lindberg, J. Persson, H. Martens, Anal. Chim. Acta 150 (1983) 61-70

[36] S. Wold, N. Kettaneh, K. Tjessem, J. Chemom. 10 (1996) 463-482.

[37] H. Martens, T. Naes, Multivariate Calibration, John Wiley and Sons, Chichester, 1989.

[38] Y. Liang, O. Kvalheim, Chemometr. Intell. Lab. Syst. 32 (1996) 1-10.

[39] D.E. Honigs, G.M. Hieftje, T. Hirschfeld, Appl. Spectrosc. 38 (1984) 317-322.

[40] H.M. Heise, R. Marbach, G. Janatsch, J.D. Kruse-Jarres, Anal. Chem. 61 (1989) 2009-2015.

[41] A. Berglund, S. Wold, J. Chemom. 13 (1999) 461-471.

[42] J. Riu, R. Bro, Chemom. Intell. Lab. Syst. 65 (2003) 35.

[43] J.A. Westerhuis, H.C.J. Hoefsloot, S. Smit, D.J. Vis, A.K. Smilde, E.J.J. van Velzen, J. P.M. van Duijnhoven, F.A. van Dorsten, Metabolomics 4 (2008) 81-89.

[44] H. Schulz, G. Özkan, M. Baranska, H. Krüger, M. Özcan, Vib. Spectrosc. 39 (2005) 249-256.

[45] H. Schulz, M. Baranska, Vib. Spectrosc. 43 (2007) 13-25.

[46] D. Lin-Vien, N.B. Colthup, W.G. Fateley, J.G. Grasselli, The Handbook of Infrared and Raman Characteristic Frequencies of Organic Molecules, Elsevier, 1991.

[47] D.M. Haaland, E.V. Thomas, Anal. Chem. 60 (1988) 1193-1202. 